\title{
USGS Mineral Resources Program A National Perspective
}

\begin{abstract}
inerals are chemical compounds abundant in the rocks, soil, and water around us and they have a profound impact on the lives of all beings. Naturally occurring minerals define the landscape in which we live. They affect our ecosystems, influence the availability of nutrients that support biota, impact the distribution of vegetation, and may also contribute to contamination of the environment. Minerals are used in fertilizers for farming, in concrete and building materials for construction, in aggregate for roads, in steel for cars and all manner of transportation, and in materials crucial to the communications industry.
\end{abstract}

The USGS Mineral Resources Program addresses mineral issues that can be grouped into three broad categories related to basic human needs for resources. The three categories and how the Program addresses them can be summed up in the following manner: (1) Environment and public health-Sources of naturally occurring contamination from mineral deposits identified and environmental impacts of mining, smelting, use, and eventual disposal of mineral products examined.

(2) Sustainability and societal need-Availability of mineral resources to sustain our standard of living without unacceptable degradation of the environment examined. (3) Economy and public policy-Information provided to government policy makers who balance the needs for economic supplies of minerals, environmental protection, responsible management of public lands, and national security.

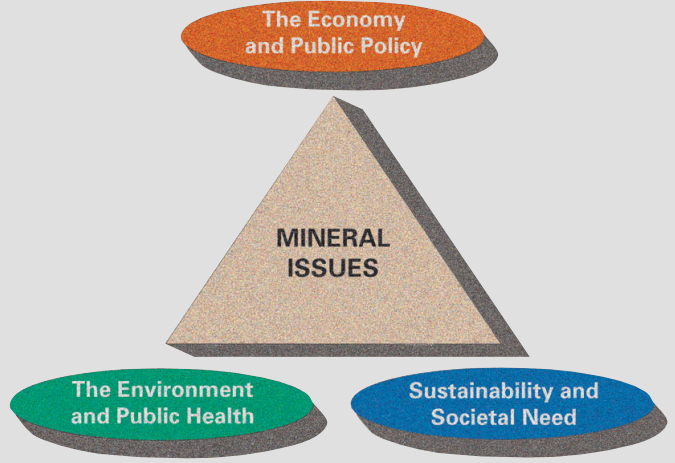

Mineral issues are related to basic human needs for resources. Federal policy and regulatory activities reflect current attitudes on the balance between the need for nonrenewable resources and maintaining environmental quality.

\section{Program M ission and Personnel}

$\mathrm{T}$ he Mineral Resources Program is the sole Federal provider of high-quality scientific information, objective resource assessments, and unbiased research results on mineral potential, production, consumption, and environmental behavior. The Program provides national minerals information, objective assessments, and high-quality applied research on all aspects of the natural and human-made minerals cycle. Information generated by the Program is used by government decision makers to formulate national and domestic

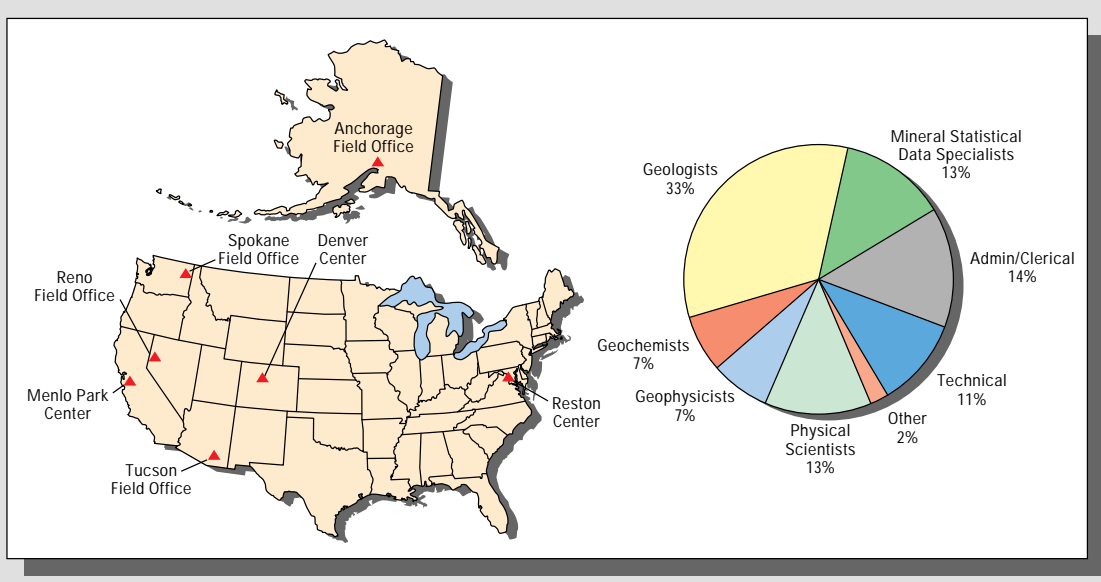
economic and environmental policy, by land managers to implement wise stewardship of public lands and resources, and by industry and academia to improve business and commerce and conduct research.

A staff of about 475 diverse specialists is organized into teams located in three regional centers and four field offices throughout the United States. Cooperative agreements between Program staff and universities, industry, and other governmental agencies provide opportunities for collaborative research and exchange of ideas and data.

Distribution of offices and specialties of personnel in the USGS Mineral Resources Program. 


\section{USGS Mineral Resources Program}

\section{Environment and Public Health}

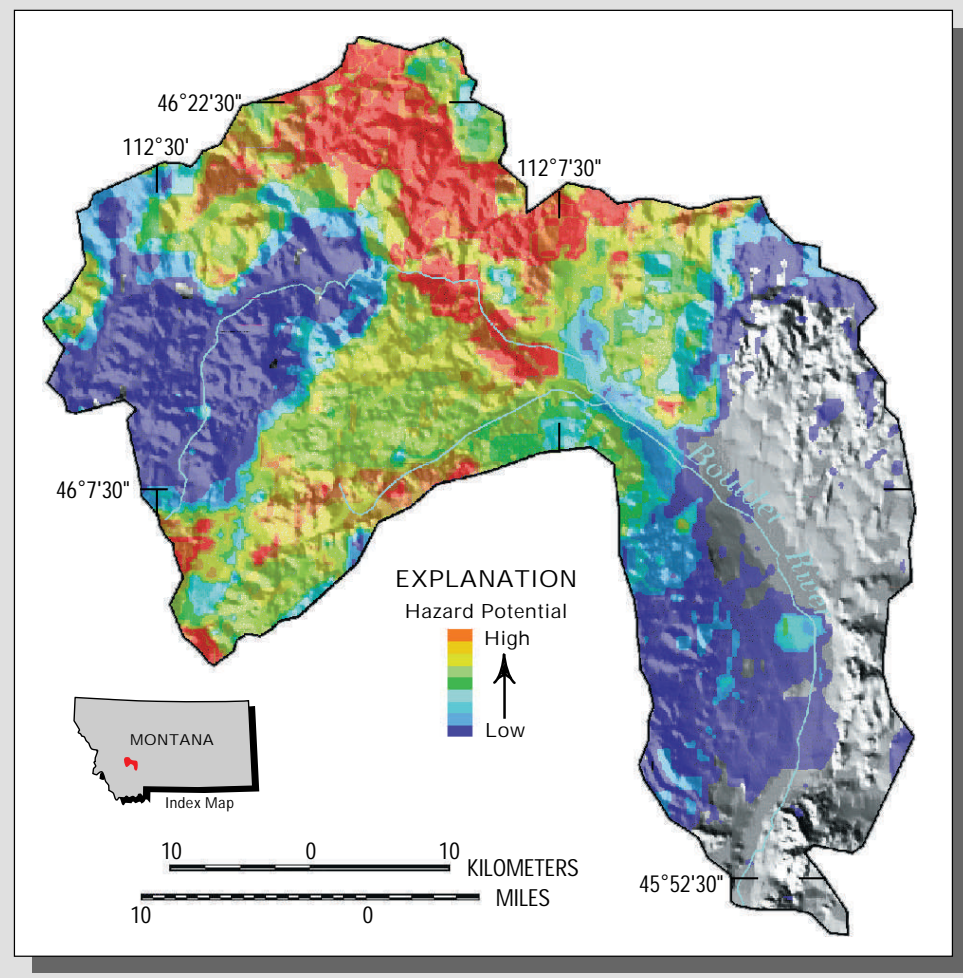

Map showing potential for hazardous mine drainage in the Boulder Creek, Montana, area created from analysis of geophysical, geochemical, and geologic digital databases. Scientific interpretation of data, understanding how deposits are formed, and evaluating the environmental contributions of minerals and mining are important Program components.
$\mathbf{P}$ rogram studies provide objective information and assessments to aid in prioritization, mitigation, and restoration of environmentally contaminated sites, as well as regulatory policy formulation related to environmental quality. Development of baseline and background geochemical databases, studies of the movement of contaminants through the environment - source, transport, and ultimate depositionand the development of state-of-the-art remote sensing and geochemical techniques are all ways in which the Program provides scientific background for environmental decision makers. Current projects are focused in four major areas:

\section{- Ecosystem Health}

Geochemistry and remote sensing techniques are used to find sources of nutrients and toxins and understand their distribution and effects on health

\section{- Abandoned Mine Land Assessments}

Ore deposit research, geochemical modeling, and remote sensing are used to understand the impact of historic mining and prioritize remediation

- Natural and Mined Mercury (Hg) and Arsenic (As) Research on geologic processes related to natural and mined occurrences of $\mathrm{Hg}$ and $\mathrm{As}$ aids in the abatement of these toxic elements

\section{- Geochemical Baselines and Backgrounds}

Geochemistry and remote sensing data are used to characterize spatially and temporally both natural and manmade concentrations of chemical elements and compounds

\section{Sustainability and Societal Need}

T he National Research Council defines sustainability as "a growing concern about the adequacy of mineral resources to meet future demands and to do so without unacceptable environmental degradation." National databases for geochemistry, lithology, geophysics, mine locality, mineral production, consumption, use, and recycling are maintained by the Program as part of the effort to identify supplies. Building on the information stored in the databases, the Program works to develop new assessment methods and supports a range of applied earth science research. Resource studies are conducted in partnership with colleagues in industry, academia, and other governmental agencies. Current projects are focused in four major areas:

\section{- Infrastructure Resources}

Integrated research on availability, quality, and environmertal impact of extracting basic resources (water, energy, and aggregate) needed for growth and renewal.

\section{- Assessment Methods}

Accurate and objective economic and environmental assessments of mineral potential

\section{- National Databases}

Compilation, analyses, interpretation, and dissemination of geologic, geochemical, geophysical, mineral locality and mine locality databases

\section{- Life-Cycle Studies of Gold and Copper}

Integrated research on ore deposits from formation through production and disposal 


\section{A Natjonal Perspective}

\section{Life Cycle M odels of a Mineral Commodity}

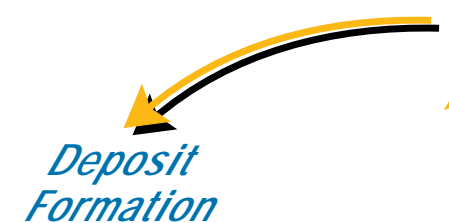

Environment
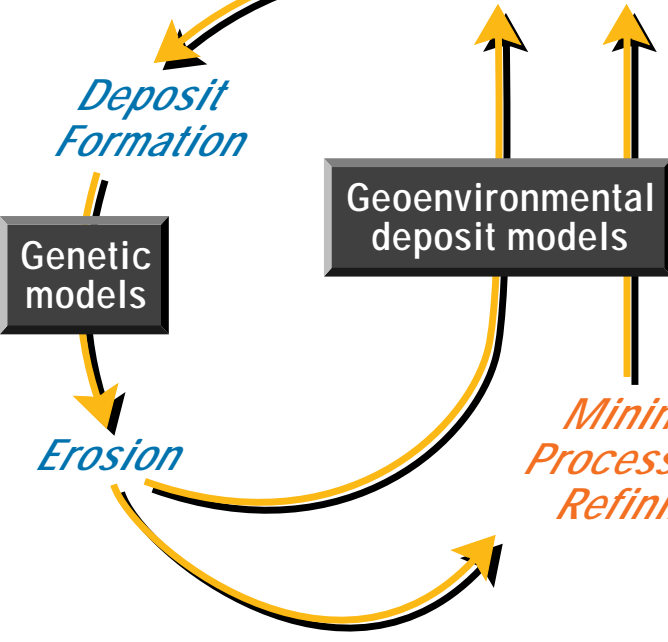

al

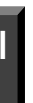

Recycling

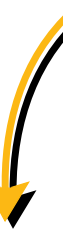

Mining,

Processing, Refining

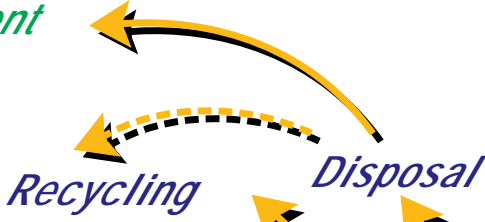

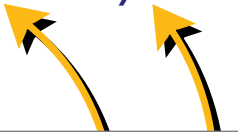

Minerals information, analysis, materials flow

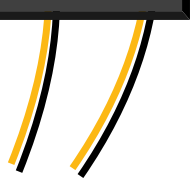

\section{Commodity Use}

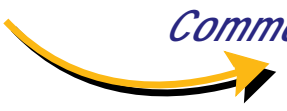

The life cycle of a mineral commodity starts with the formation of a deposit that when eroded or mined may introduce minerals and elements (some toxic) into water and sediments. The USGS studies deposit formation and derives genetic models that describe the physical properties of deposit types, including grade and tonnage. Geoenvironmental models build on genetic models with information that can be used to forecast metal loadings, $\mathrm{pH}$, and buffering capacity of mineral deposits based on geologic and climatological constraints. Mining, processing, and refining provide the interface between the natural mineral cycle and the human-derived part of the cycle in which mineral products are used, recycled, and ultimately disposed of, which may affect the environment. The USGS reports on mineral commodity use, analyzes economic trends, and studies the flow of materials through the environment and the economy.

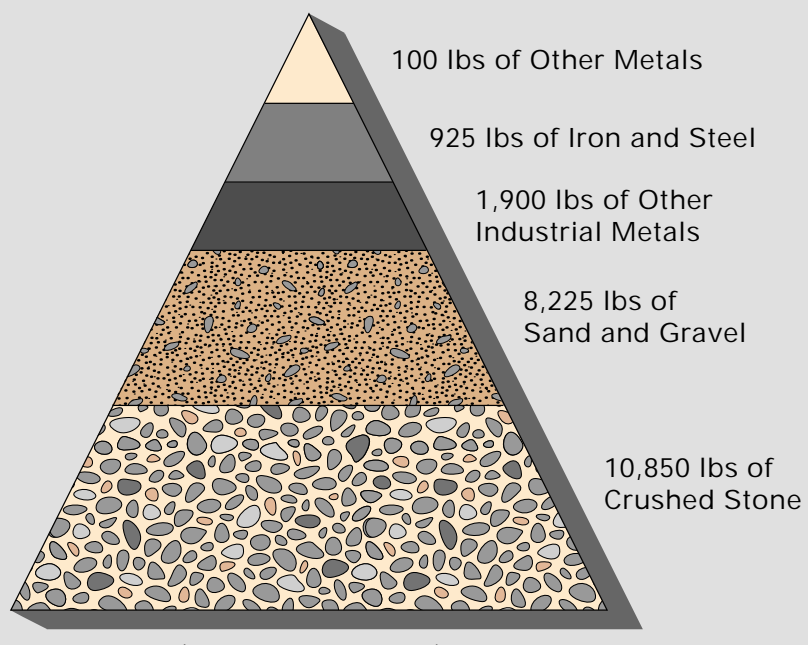

(Estimates for 1996)

Annual consumption per person in the United States of selected mineral commodities. USGS Mineral Resources Program personnel compile data and distribute information from the U.S. and 190 countries on more than 100 commodities.

\section{Mid-Atlantic Geology and Infrastructure Case Study}

ontinued population growth and urbanization in the urban corridors of the eastern United States, where existing infrastructure needs improvement and expansion, will generate huge demand for construction materials.

Virtually all domestically mined aggregate is used locally. Over the last 30 years, competition between many possible uses for both lands and resources has become increasingly complex, and the aggregate industry has seen significant changes. However, we lack comprehensive analyses of changes to the industry and trends in sources, aggregate quality, haul distances, prices, and other factors that control aggregate availability.

The Baltimore-Washington urban corridor has been chosen as a target area for these types of analyses because good resource information is available and it is one of the Nation's fastest growing metropolitan areas. Results of this study will help planners in other areas predict trends in availability, consumption, and use of aggregate resources, essential information for planning for future resource needs. 


\section{Economy and Public Policy}

- $\mathrm{n}$ order to balance the demand for an abundant mineral supply with the desire to maintain environmental integrity and public health, government policy makers need national and regional long-term data on mineral potential, production, use, and recycling. Analysis of the flow of mineral materials through the entire economic cycle is essential for effective mineral conservation and recycling, stewardship of Federal lands, and the development of environmental policy. Current projects are focused in four major areas:

\section{Land Stewardship}

Studies conducted in coordination with Federal land management agencies focus on mineral potential and environmental quality and are used in the development of management plans

- National and International Commodity Studies Collect, synthesize, analyze, and disseminate information on more than 100 commodities for more than 190 countries worldwide

- Mineral Conservation and Materials Flow Collect, synthesize, analyze, and disseminate information on supply, consumption, production, trade, trends, use, reuse, disposal, and economic impacts for improved resource utilization

\section{- Special International Studies}

Working groups of international scientists address global issues related to mineral resources, the supply of mineral commodities, and environmental concerns

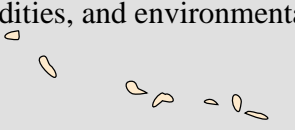

$$
\theta_{\infty}=0
$$

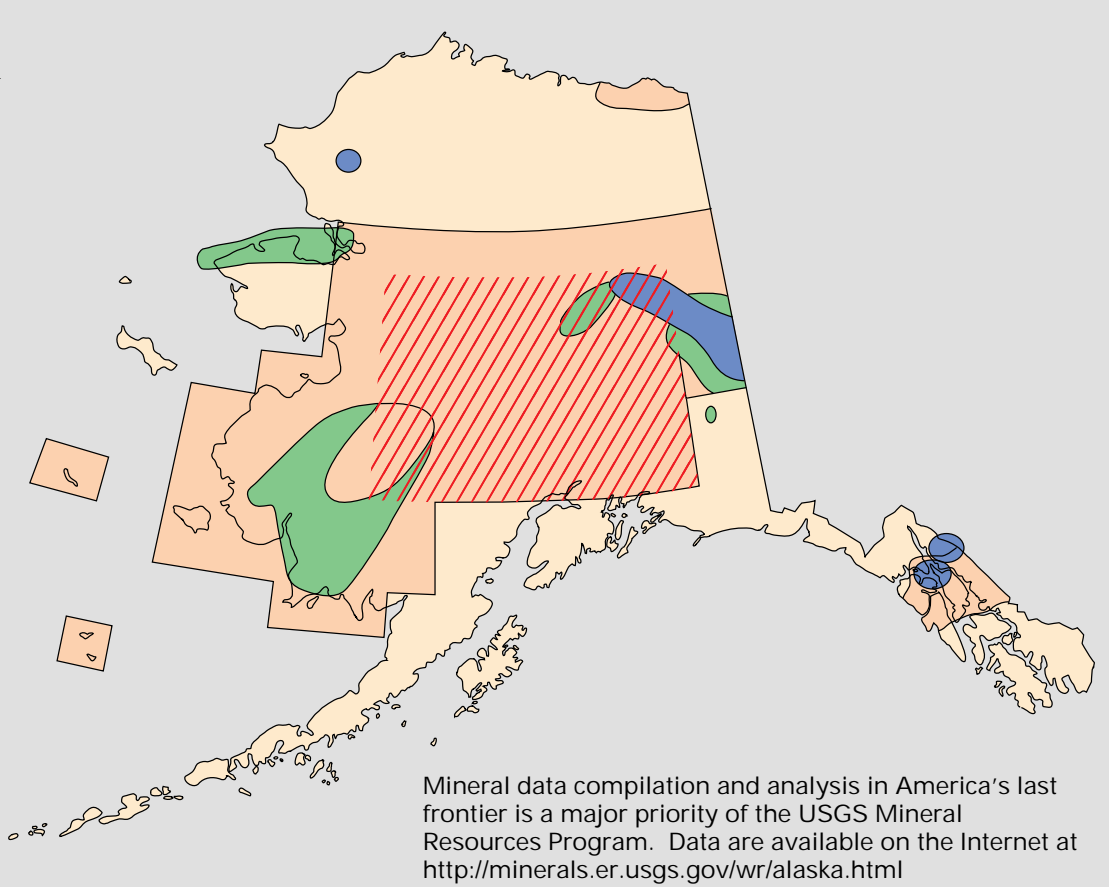

Land Stewardship and Surveys and Analysis Studies-Compilation, analyses, and dissemination of digital geologic, geochemical, and geophysical data for use in resource and environmental assessments to support stewardship of Federal lands, which comprise 60 percent of the State. Red line pattern indicates area of current geologic mapping and compilation in cooperation with the Alaska Division of Oil and Gas

Environmental and Public Health Studies-Research on the bioavailability of arsenic and mercury in the environment, conducted with the USGS Biological Resources Division. Geochemical baseline assessments conducted in cooperation with the National Park Service. Life cycle studies of mercury deposits in partnership with Federal land management agencies, industry, and community stakeholders

Life Cycle Studies of Ore Deposits-Research on gold and massive sulfide deposits conducted in partnership with Federal land management agencies, Alaska Division of Geological and Geophysical Surveys, industry, and community stakeholders 